\title{
Otras violencias, otros silencios: tecnologías del hipermercado global vs. técnicas del mercado popular
}

\author{
Andrés F. Castiblanco Roldán*
}

\section{Introducción}

La globalización trajo consigo una serie de transformaciones espaciales que se desarrollaron en los países que conforman la configuración del mercado mundial. La experiencia del intercambio a una escala planetaria vino con una suma de actores y acontecimientos que reforzaron los bloques económicos de fines de siglo XX; experiencia que se gestó en sociedades interconectadas y concomitantes con el avance de las comunicaciones y las modernas renovaciones del transporte.

Esta neomodernización no implicó la desaparición de los grupos hegemónicos, aunque en la integración de un sistema-mundo y en el posicionamiento

\footnotetext{
* Profesor de la Facultad de Ciencias y Educación de la Universidad Distrital Francisco José de Caldas. Estudios doctorales en Ciencias Humanas y Sociales en la Universidad Nacional de Colombia. Investigador del grupo "Literatura, Educación, Comunicación”. Correo electrónico: geoandes@hotmail.com
} 
de las ciudades como aldeas planetarias se dejaron de lado algunas costumbres frente a las nuevas maneras de ver, esto es, nuevas prácticas llegaron con la entrada de las naciones a un escenario global de los mercados.

$\mathrm{Al}$ respecto, Bauman (2005) afirma:

Donde quiera que se ejecutaran esos planes, los intentos de "homogeneizar" el espacio urbano, volverlo "lógico", "funcional" o "legible" provocaban la desintegración de las redes de protección de los lazos humanos y la experiencia psíquicamente destructiva del abandono y la soledad, sumadas a un vacío interior, el miedo a los desafíos que puede traer la vida y un analfabetismo funcional de tomar decisiones autónomas y responsables (p. 63).

La idea de Bauman apunta hacia las especializaciones de los lugares y hacia el ejercicio de anonimatos que ponen en la cuerda floja el ejercicio de las identidades colectivas de generar apegos y memorias. Concordando con la anterior cita de Bauman respecto a los términos "funcional", "lógico" y "legible", se puede decir que en la propuesta globalizadora se busca constituir, a través de lógicas renovadas, formas funcionales legibles desde cualquier punto de vista (no solo psíquico o simbólico, sino también territorial). De allí que los procesos de transnacionalización lograran un efecto de marca y de adquisición de identidades mundializadas y de costumbres encarnadas en estas maneras-técnicas contemporáneas de entender el mundo.

Dentro de este marco, la propuesta del texto se centra en analizar las estrategias que vienen desplazando el lazo tradicional del mercado popular -que tiene a la plaza como anclaje con el pasado-, por la generación de grandes superficies, centros comerciales e hipermercados de las ciudades actuales. Estas estrategias se pueden caracterizar en ejercicios de monopolio, en alianzas con la política pública y en las paradojas de la imagen y la marca sobre el territorio. Con ello se soslaya y favorece la marginación 
creciente en el espacio y, en suma, se contribuye a la violencia simbólica sobre campesinos, desplazados y obreros por parte de otros grupos sociales.

Una de las posturas argumentadas frente a la presente disertación habla de que no sorprenden las estructuras microeconómicas en las que se ubican estos mercados, pues actúan en las macroestructuras como engranajes que funcionan e interactúan. Esta lectura no requiere mayor análisis sobre las relaciones que se establecen en los intercambios de estos escenarios y asume, entonces, que tales estructuras microeconómicas se dan desde la necesidad y la supervivencia. Este es un argumento fuerte, pero naturaliza los trámites simbólicos de dominación que han sido estudiados por Bourdieu (1997) en Sociología y que son importantes para entender el entramado de relaciones que se dan en las prácticas cotidianas.

En este sentido es pertinente pensar lo cotidiano: descifrar los códigos de los agentes en los medios sociales y entender los modos en que interactúan o se modifican las costumbres o hábitos que se han transmitido gracias a una memoria técnica; esa memoria del grupo que afianza las formas de sobrevivir al trascender el acto de existir y al crear normas y tácticas sociales que hacen particular, en este caso, unos modos de vivir lo económico.

Para algunos románticos de lo popular (Hudder, 1965; Rondinelli, 1987; Durston, 1992) se trata de retornar al refugio de la conservación de intercambios simbólicos y mercantiles originarios, al igual que a su propagación en el cada vez más complejo sistema de los mercados informales que se acentúan en las periferias de las ciudades.

Otros más escépticos (Richardson, 2004; Low y Lawrence, 2003; Besnier, 2004; Bromly, 1975; Castillo, 1983) definen las costumbres como resistencias del campesinado a través de las prácticas que permanecen en un anonimato conveniente para la supervivencia. Asechados incluso por las intervenciones estatales en nombre de los derechos comunes como el espacio público y el comercio legal -con los cuales salen a flote los conflictos 
vigentes de estas guerras de mercado-, estos procesos de memoria y sobrevivencia permanecen, sin embargo, en la cotidianidad.

Brevemente, en este texto se presentan algunos elementos para pensar los mercados populares en clave de memoria. Cabe aclarar que no se va a disertar sobre las teorías de la memoria, ya que para ahondar en estas se pueden ver trabajos que complejizan su uso y disposición como concepto (Castiblanco, 2011, 2009; Jimenez y Guerra, 2009). En este caso, la memoria está implícita en el carácter preservador de las prácticas, sea por los rasgos populares, analizados por teóricos como Joel Candau en su Antropología de la memoria o desde la perspectiva de lugar en que se ubica Pierre Nora, por la imaginación del tiempo propuesta en Jacques Le Goff o por la narración como vehículo de un tiempo en acción según Paul Ricœur.

Los elementos que se presentan se han ido desarrollando a partir de los comentarios de lectores y estudiantes de seminarios como Modernidad y Posmodernidad o Análisis del Discurso, la Imagen y el Consumo de la Licenciatura en Educación Artística y la Maestría en Investigación Social Interdisciplinaria de la Universidad Distrital. Particularmente se ha abordado la cuestión de dicotomizar los procesos de lo popular, de lo nemónico $\mathrm{y}$, en consecuencia, partir de dos parcialidades cuando las cuestiones de la memoria y las dinámicas sociales se presentan como tramas que se encuentran en constante cambio de posición. En este sentido no se trata de apologizar lo popular ni de establecer un lugar común a la crítica de actores y evidencias; se trata, por ahora, de plantear un panorama de relaciones vigentes en la relación entre mercados populares, comercio y territorio.

\section{El mercado y sus metáforas}

El concepto común de mercado habla de un ambiente social donde se propician relaciones de intercambio y donde hay una constante interacción entre compradores y vendedores. En este ambiente existen operaciones asociadas a la circulación de las mercancías y a la relación de aumento o disminución 
de precios y valores. Según la Real Academia de la Lengua Española, el mercado es, en primer término, un sitio público destinado permanentemente, o en días señalados, vender, comprar o permutar bienes o servicios. En segundo término es el conjunto de actividades realizadas libremente por los agentes económicos sin intervención del poder público. También es el conjunto de operaciones comerciales que afectan a un determinado sector de bienes; o la plaza o país de especial importancia o significación en un orden comercial cualquiera. Finalmente, tratando de ver su concepto desde el consumo, la Real Academia (2001) define al mercado como el conjunto de consumidores capaces de comprar un producto o servicio, llegando a su definición formulaica como estado y evolución de la oferta y la demanda en un sector económico dado.

Podría pensarse que la visión cultural de estas definiciones usadas y consultadas está sumergida en los pliegues de dichas concepciones. También podría afirmarse que definitivamente estos esfuerzos generalizantes se quedan cortos ante la necesidad de contemplar las tendencias interpretativas del mercado en sus especificidades más humanas, con respecto a los análisis comerciales y financieros en la globalidad del mercado de la actualidad ${ }^{1}$.

No obstante, el presente texto se circunscribe en el horizonte urbano del mercado, en la escala esencial de las relaciones que constituyen su realidad: el micromercado, el comercio de la calle, el supermercado, la tienda, hasta llegar a las grandes superficies y centros comerciales. Este trabajo también se centra en la interacción social en la cual fluyen finalmente todas las tendencias globales y nacionales de las conductas económicas, es decir, en la escenificación de acciones y repertorios que se pueden mirar desde lo cultural para analizar sus mecanismos de interacción.

1 En la geografía mundial hay varios trabajos sobre la cuestión financiera, pero hay estudios que conciben el concepto de "mercados emergentes" para hacer referencia a las fluctuaciones comerciales que se originan al margen de las economías globales de mercado, y que a pesar de ser periféricos, captan la atención de inversores de todo el mundo. Al respecto, véase Sidaway y Pryket (2000, pp. 187-210). 
Sociológicamente se ha establecido la discusión frente a la teoría económica. Lie (1997) en Sociology of markets permite entender que este concepto/campo ha carecido, posiblemente, de una perspectiva interdisciplinaria para definir algunos fenómenos asociados al universo conceptual del mercado. Así como la referencia al espacio constituye un entorno dinamizador, o de la misma forma como el sujeto transformador establece posibilidades de estudio o la memoria en tanto camino y lugar experimenta sentidos múltiples, asimismo en la visión de la presente propuesta es importante desbordar al mercado más allá de la perspectiva y enfoque económico y funcional con que se ha tomado en la mayoría de estudios, salvo los que se ubican en el campo del consumo (Ewen, 1991; Merton, 1995). Estos últimos ya pertenecen al campo sociológico, donde hay una apuesta sobre los elementos simbólicos que se ponen en juego en este conjunto de relaciones (sobre estos trabajos se hará referencia más adelante).

En este sentido es importante pensar el mercado como un conjunto de relaciones y artefactos en circulación permanente, aun cuando Lie (1997, p. 342), al introducir su texto, describa la ambigüedad del concepto y las concepciones que ha tenido para economistas como Smith. Este último lo definía como el hueco central en el corazón de la economía, en tanto la versión sociológica de Friedman aduce que la característica central de la técnica del mercado es la de lograr la coordinación-armonía de la simple economía de intercambio. En resumen, para Lie esto último era el mercado neoclásico despojado de las relaciones sociales, instituciones o tecnologías y, por tanto, carente de elementales preocupaciones sociológicas como la energía, las normas y las redes.

La historia de Braudel (1984) nos refiere algunos rasgos de los mercados y comercios urbanos, que representan la variedad de relaciones y las identificaciones de las ciudades con sus comercios. El autor propone:

Los mercados urbanos hacen tangible, en todas partes, esta función de movimiento. Un viajero podría decir de Esmirna, en 1963, que "no era 
más que un bazar y una feria", pero toda ciudad, cualquier ciudad, era ante todo un mercado (Braudel, 1984, p. 438).

Esta metáfora bien podría matizar una caracterización de las calles bogotanas, las cuales simbolizan toda clase de representaciones urbanas plasmadas en fachadas, vitrinas, letreros y situaciones cotidianas.

\section{Políticas urbanas y espacio público}

Para pensar el análisis de las políticas públicas de forma tangente o directa, se pone sobre la mesa el carácter regulador de estas, de la mano de los dispositivos que permiten el agenciamiento de las costumbres en la población (Sáenz, 2007; Outtes, 2005), desde permanencias hegemónicas (Barbosa, 2005) y exclusivas, hasta intentos de pedagogización de lo ciudadano y de su ética urbana (Sáenz, 2009). El elemento de coerción y organización espacial de la política pública urbana se sustenta, entre otros aspectos, en la defensa del espacio público por sobre cualquier interés (Jiménez, 2001; Beltrán, 2003). Finalmente, la falta de continuidad con los programas de gobierno producen las fracturas sobre las concepciones del espacio urbano, generando materialidades fragmentadas y formaciones discursivas excluyentes del espacio (Serna, 2006; Sanabria, 2009). Para este último autor, la posibilidad de recuperación y democratización se basa en el análisis de las dinámicas urbanas, donde puede enfocarse en tres polos fundamentales de la vida social: la ley, la moral y la cultura. En este caso es muy pertinente la relación que establece Sanabria con referencia a la relación cultura-economía, pues la primera permite la construcción de una ética civil sin separarse de la segunda, permitiendo, por consiguiente, entender lo urbano en una metáfora de actores y espectadores involucrados en una tramoya colectiva.

Brevemente se puede comentar que el ubicar la filosofía de las políticas públicas urbanas permite entender la manera como se interactúa desde el Estado con los mercados populares, cuál es la mano directa de la ley sobre 
los lugares de abastecimiento de productos agrícolas y cuáles son las medidas policivas frente al cumplimiento de los mercados móviles y frente al control de la informalidad, la piratería y el contrabando. En este panorama resulta interesante entender la ética o moralidad del espacio urbano en relación con el control o regulación de la marca y su difusión desde la política urbana, y qué tensiones genera la imposición de medidas que siempre buscan un bienestar de un sector poblacional en soslayo de otro.

\section{Informalidad, ambulantaje y economías subterráneas}

Se podría estar hablando de una tendencia muy fuerte hacia el estudio de los mercados urbanos: pensar su desarrollo desde sus factores de riesgo, es decir, pensar que fruto de las políticas públicas urbanas -cuya filosofía entra en tensión con lo marginado (Sáenz, 2007)-, la visión que existe se origina desde los índices de pobreza, desplazamiento, economías subterráneas y, finalmente, informalidad o estabilidad amorfa (aquí lo legal e institucionalizado se concibe como lo formal del mercado urbano). En este sentido lo presentan informes oficiales sobre mercados callejeros en Bogotá (Cámara de Comercio de Bogotá [CCB], 2005) e informes de entes conformados para su estudio, como el Observatorio de la Región Bogotá-Cundinamarca (CCB, 2009), que configuran maneras contemporáneas de ver las tramas de interacción del comercio en la ciudad.

Sin embargo, además de los informes, es valioso mirar cómo se ha pensado la cuestión desde otros puntos de vista. Una referencia clásica es la de Bromley et ál. (1975, 1998, 2009). El trabajo de estos autores permite observar una serie de ritmos urbanos que hacen posible analizar el paso que dieron los mercados periódicos a la circulación diaria. El enfoque es interesante por cuanto devela la relación entre los mercados periódicos y los establecimientos fijos; situación que se refleja más en las fluctuaciones del comercio informal, que a pesar de presentarse como transgresión al espacio de mercado de los negocios fijos, se beneficia de la permanencia de estos 
últimos para garantizar una clientela o demanda regular (Bromley et ál., 1975, 1998, 2009). Estaríamos hablando de unas relaciones espacialmente parasitarias con respecto a los establecimientos fijos, por cuanto hay una relación directa entre las diversas zonas clasificadas por productos y sus correspondientes vendedores informales.

Un trabajo más reciente de Bromley permite visualizar las tendencias de las relaciones que se establecen entre los locales comerciales en Quito. Para Bromley (1998), la propagación mundial del supermercado y del centro comercial es el proceso que configura la transformación de los locales comerciales en la ciudad de América Latina. Gran parte del dinamismo del comercio de plaza se asocia con la intervención del gobierno, con las principales políticas como la creación de los mercados menos atendidos en las zonas urbanas y con la reducción en la concentración del comercio popular en zonas céntricas (Bromley, 1998).

En Cuzco, Bromley y Mackie (2009) realizan un último trabajo de análisis del desplazamiento de los comerciantes informales de la zona céntrica, a causa de las políticas gubernamentales en pro del espacio público y del aprovechamiento del turismo (Bromley \& Mackie, 2009). Este es otro factor que tiene una directa relación con la marca y con la imagen sustentada en ficciones comerciales, las cuales están representadas desde un patrimonio que se muestra como un paisaje sin gentes que puedan degradarlo en su exhibición.

Junto al trabajo de Bromley, hay estudios en países como México a partir de los cuales se han acuñado términos como el de "ambulantaje", el cual hace referencia a la trashumancia o nomadismo de comerciantes que no están instituidos en el marco legal indicado por las políticas de industria y comercio para el espacio público (para el caso colombiano se trataría de la informalidad). J. Cross, en principio preocupado por el desplazamiento de lo que se ha denominado "el ambulantaje del centro del Distrito Federal", encontró cómo la política del Partido Revolucionario Institucional (PRI) llevó a los comerciantes a agremiarse y militar en este partido en función de 
proteger sus derechos (Cross, 1996). Posteriormente esta política se concentró en los procesos de negociación con comerciantes, dado el debilitamiento, tiempo después, del cuerpo electoral del PRI en el escenario popular (Cross, 1997). Este trabajo permite dimensionar el papel de los mercados populares y del comercio informal en los movimientos políticos en relación con lo masivo, categoría que interviene en el orden de las relaciones observadas y, además, integra un panorama de investigación que ha ocupado especialmente a los analistas económicos y, por supuesto, a los urbanistas.

Por último, en Colombia el concepto de "economía subterránea" agrupa la informalidad de los mercados populares, por relacionarla directamente con fenómenos como el contrabando y el narcotráfico ${ }^{2}$. Esta definición propia de economistas y politólogos plantea otra visión de lo informal:

Podemos decir que comprende todas las actividades económicas en el campo de la producción y la distribución de bienes y servicios que, o no cuentan con las autorizaciones legales correspondientes, o son productos cuyo consumo es ilegal. En este sentido, la economía subterránea comprende desde el vendedor de los semáforos hasta el narcotráfico (Gómez y Santamaría, 2007, p. 269).

Esta es otra arista que se suma a la tendencia que estudia los mercados urbanos desde lo informal y, en este caso, desde lo ilegal.

2 El 14 de mayo de 2012, el diario El Espectador publicó un artículo que informaba que uno de los principales lugares de entrada de armas y drogas a Bogotá era la plaza Corabastos. 


\section{Para cerrar y abrir un campo}

\section{La caracterización de los actores del mercado popular urbano: sus acciones, códigos e imágenes}

El punto de partida de varios estudios sobre esta cuestión es la globalización, la transnacionalización y sus consecuencias en los mercados internos de los países del tercer mundo, economías urbanas y territorialidades signadas por el mercado y lo masivo, en tanto horizonte donde se solapan la pobreza y el conflicto social (Roccietti, 2000; Lyons y Snoxell, 2005a, 2005b; Mooya y Cloete, 2007). En el interior de las dinámicas del mercado, las caracterizaciones de quienes interactúan y la pregunta por cómo configuran sus espacialidades tiene un importante acercamiento a partir de trabajos que buscan entender las redes formadas en los mercados urbanos, los intercambios y las formas de sociabilidad (Spillman, 1999; Besnier, 2004). Estas últimas van desde las relaciones con una neorruralidad y la apropiación de un sistema-ciudad contemporáneo, hasta la generación de nuevos tipos de relación en los espacios ocupados (Lins, 1999; Watson, 2009). Además de estas tendencias interpretativas, también se encuentran los acercamientos que más se ubican en el horizonte de la comunicación, la estética y sus intercambios simbólicos:

La comercialización y la producción no están separadas, sino bien cerca la una de la otra. Y en esta economía (popular), las relaciones familiares son fundamentales y se hacen visibles directamente en el puesto mismo de trabajo: el vendedor no es el individuo sino la familia entera, el marido, la esposa y los hijos son los que cargan los productos, los organizan, los publicitan, los reponen y venden. En el supermercado la relación constitutiva es otra, la inversa: un solo dueño -invisible- y todos los demás trabajadores asalariados (Martín-Barbero, 1981, p. 3). 
Martín-Barbero pretende posicionar la experiencia alterna en comunicación, criticando el descuido intencional y totalizante de lo transnacional sobre la calidad de esta serie de relaciones que implican formación de identidades y comportamientos frente a lo urbano. Otra perspectiva interesante aterrizada sobre la imagen se encuentra en la estética del consumo y en la masificación de los mercados urbanos, donde hay una mirada sobre la configuración de la marca y las implicaciones que esta tiene sobre la arquitectura y la organización del espacio metropolitano (Julier, 2005). Con ello se articulan tanto los códigos de los intercambios entre actores como la imagen y la marca que agrupan y estructuran la materialidad de la calle y de otros lugares.

Por último, pero no menos importante, está la apuesta desde lo visual en la cultura material que expone Sanín (2008a, 2008b). El autor nos pone en contacto directo con los sistemas de objetos que teóricamente ha trabajado Baudrillard y nos propone, para este caso, la necesidad de trabajar con la marca como imagen del consumo de una serie de objetos que están en el repertorio de los mercados populares, sobre cuyos intercambios ocurren relaciones que van desde la movilidad hasta la configuración de territorios.

Para cerrar y a la vez dejar abierto el campo, la contribución de esta propuesta puede insertarse en el debate de la presencia de códigos y transferencias culturales, que permiten el fortalecimiento de un tejido social inmerso en las relaciones del mercado urbano y, por tanto, generador de espacios sociales que dinamizan su posicionamiento frente a las economías de gran escala, fruto de los procesos de inversión que trajo la globalización y la transnacionalización de la economía.

No se trata de tomar posturas antiestatales o paternalistas hacia manifestaciones que se han reducido al concepto de lo popular, lo subterráneo, lo informal, lo pobre, lo marginal en otros estudios. Lo que se pretende es dimensionar de forma interdisciplinar y crítica un fenómeno que se presenta en la cotidianidad y que parte de su expresión se materializa en los 
conflictos de los comercios informales y sus luchas por el espacio, en las políticas públicas sobre los mercados informales -en las cuales entran las regulaciones de las plazas-, en las medidas que se toman alrededor del control de precios entre las instituciones decisorias-dominantes y en los acuerdos de las agremiaciones que se ven representadas en plazas y comercios callejeros. Estas son otras violencias y otros escenarios donde la memoria tiene mucho por decir, desde la presencia de la herencia técnica que se plasma en los intercambios del comercio, hasta las tecnologías que entran en juego a partir de legitimidades estatales y posiciones de consumo. Allí conviven formas simbólicas que niegan los intercambios simplemente económicos y, por tanto, asumen otras transferencias simbólicas.

\section{Referencias}

Barbosa Cruz, M. (2005, julio-diciembre). Proyectos de modernización y urbanización en México y Bogotá, 1880-1930. Revista Memoria y Sociedad, 19(9). Bogotá: Pontificia Universidad Javeriana.

Bauman, Z. (2005). La globalización: consecuencias humanas. México: Fondo de Cultura Económica.

Bauman, Z. (2009). Modernidad líquida. México: Fondo de Cultura Económica.

Beltrán Gómez, D. (2003). Sobre las razones de creación de la Defensoría del Espacio Público y sus resultados. En Salazar, C., Cendales, D. et ál. Bogotá y lo público (pp. 102-112). Bogotá: Universidad de los Andes.

Besnier, N. (2004). Cosumption and cosmopolitanism: practicing modernity at the second hand market place in Nukui Alufa Tonga. Antropogical Quartely, 1(77), 7-45.

Bourdieu, P. (1997). Razones prácticas. Sobre la teoría de la acción. Barcelona: Anagrama. 
Braudel, F. (1984). Civilización material, economía y capitalismo, siglos XV-XVIII (vol. 2: Los juegos del intercambio). Madrid: Alianza.

Bromley, R. et ál. (1975). The rationale of periodic markets. Annals of the Association of American Geographers, 4(65), 530-537.

Bromley, R. (1998). Market-place trading and transformation of retail space in the expanding Latin American city. Urban Studies Fournal, 35(46), 1311-1333.

Bromley, R. \& Mackie, P. (2009). Displacement and the new spaces for informal trade in the Latin American city centre. Urban Studies, 7(46), 1485-1506.

Camara de Comercio de Bogotá (2005). Efecto de las ventas callejeras sobre establecimientos de comercio en cuatro zonas de la ciudad de Bogotá. Bogotá.

Camara de Comercio de Bogotá (2009, diciembre). Boletín No. 6 del Observatorio de la Región Bogotá-Cundinamarca. Bogotá.

Castillo, H. (1983, julio-septiembre). El mercado de la Merced antes del cambio. Revista Mexicana de Sociología, 3(45), 857-875.

Castiblanco, R. A. (2011). Las plazas de mercado como lugares de memoria en la ciudad: anclajes, pervivencias y luchas. Ciudad Pazando, 2(4). Bogotá: Universidad Distrital Francisco José de Caldas.

Castiblanco, R. A. (2009). Los fines de la memoria y la memoria como fin: herramientas para observar la sociedad, la escuela y el conflicto. En Serna, A. (Comp.). Memorias en crisoles: propuestas teóricas, metodológicas y estratégicas para los estudios de la memoria. Bogotá: Universidad Distrital Francisco José de Caldas.

Cross, J. (1996, abril-junio). El desalojo de los vendedores ambulantes: paralelismos históricos en la ciudad de México. Revista Mexicana de 
Sociología, 2(58), 95-115. México: Universidad Nacional Autónoma de México.

Cross, J. (1997, octubre-diciembre). Debilitando al clientelismo: la formalización del ambulantaje en la Ciudad de México. Revista Mexicana de Sociología, 4(59), 93-115. México: Universidad Nacional Autónoma de México.

Durston, J. W. (1992). Organización social de los mercados campesinos del centro de Michoacán. México: Instituto Nacional Indigenista.

El Espectador (2011, 14 de mayo). ¿Zona franca para el crimen? Recuperado de http://www.elespectador.com/impreso/bogota/articulo269840-zona-franca-el -crimen

Gómez Restrepo, H. y Santamaría Salamanca, M. (2007). La economía subterránea en Colombia. En Gran enciclopedia de Colombia (tomo II: Economía). Bogotá: Círculo de Lectores.

Hudder, B. H. (1965). Some comment on the origins of traditional markets in Africa South of the Sahara. Transactions of the Institute of British Geographers, 36, 97-105.

Jiménez Reyes, L. (2001). Organización espacial y región en Colombia. En Delgado, Jiménez, Carrizosa et ál. Espacio y territorios. Razón, pasión e imaginarios. Bogotá: Universidad Nacional de Colombia.

Julier, G. (2005). Urban design scapes and the production of aesthetic consent. Urban Studies, 5-6(42), 869-887.

Lie, J. (1997). Sociology of markets. Annual Revieres of Sociology, 23, 341-370.

Lins Ribeiro, G. (1999). La condición de la transnacionalidad. Revista Maguaré, 14, 41-74. Bogotá: Universidad Nacional de Colombia, Departamento de Antropología. 
Low, S. \& Lawrence, D. (2003). The antropology of space and place: locating culture. Estados Unidos: Blackwell Publishing.

Lyons, M. \& Snoxell, S. (2005a). Creating urban social capital: some evidence from informal traders in Nairobi. Urban Studies, 742), 1077-1097.

Lyons, M. \& Snoxell, S. (2005b). Sustainable urban livelihoods and market place social capital: crisis and strategy in petty trade. Urban Studies, $8(42), 1301-1320$.

Martín-Barbero, J. (1981). Prácticas de comunicación en la cultura popular: mercados, plazas, cementerios y lugares de ocio. En Simpson, M. (Comp.). Comunicación alternativa y cambio social. México: Universidad Nacional Autónoma de México.

Merton, R. (1995). Teoría y estructura sociales. México: Fondo de Cultura Económica.

Mooya, M. M. \& Cloete, C. E. (2007). Informal urban property markets and poverty alleviation: a conceptual framework. Urban Studies, 1(44), 147-165.

Outtes, J. (2005). Disciplinando a la sociedad por medio de la ciudad: la génesis de la planeación de ciudades en Brasil y en Argentina (18941945). Revista Maguaré, 19, 41-74. Bogotá: Universidad Nacional de Colombia, Departamento de Antropología.

Richardson, M. (2004). Being-in-the market versus being-in-the plaza: material culture and the construction of social reality in Spanish América. American Ethnologist, 9(2), 421-436.

Riocchetti, A. M. (2000). La cultura como verdad: pobreza latinoamericana. Revista Nómadas: Trabajo, Globalización e Inequidades, 12, 38-49. Bogotá: Universidad Gentral. 
Rondinelli, D. A. (1978). Urbanization and rural development: a spatial policy for equitable growth. Nueva York: Praeger.

Rondinelli, D. A. (1987). Cities as agricultural markets. Geographical Review, 4(77), 408-420.

Rondinelli, D. A. (1988). Método aplicado de análisis regional. Bogotá: Banco Central Hipotecario.

Sáenz, J. (2007). Desconfianza, civilidad y estética: las prácticas formativas estatales por fuera de la escuela en Bogotá, 1994-2003. Bogotá: Instituto para la Investigación Educativa y el Desarrollo Pedagógico - Universidad Nacional de Colombia.

Sáenz, J. (2009). La pedagogía ciudadana en Bogotá: ¿un proyecto autoritario o el mínimo común necesario para la construcción de una democracia radical? Revista Educación y Ciudad, 17, 23-36. Bogotá: Instituto para la Investigación Educativa y el Desarrollo Pedagógico.

Sanabria, F. (2009). De tramoyeros a tramoyistas. Consideraciones cívicas para un pacto ético en Colombia. Revista Educación y Ciudad, 16, 7-26. Bogotá: Instituto para la Investigación Educativa y el Desarrollo Pedagógico.

Sanín, J. D. (2008a). Estéticas del consumo: configuraciones de la cultura material. Medellín: Universidad Pontificia Bolivariana.

Sanín, J. D. (2008b, julio-diciembre). Hogar en tránsito: apropiaciones domesticas de la vivienda de interés social (VIS) y reconfiguraciones del sentido del hogar. Revista Antípoda, 7, 31-62. Bogotá: Universidad de los Andes.

Serna Dimas, A. (2006). Ciudadanos de la geografía tropical. Fïciones históricas de lo ciudadano. Bogotá: Universidad Distrital Francisco José de Caldas. 
Sidaway, D. \& Pryket, M. (2000). The strange geographies of emerging markets. Transactions of the Institute of British Geographers, 2(25), 187-210.

Spillman, L. (1999). Enriching exchange: cultural dimensions of markets. American Fournal of Economics and Sociology, 4(58), 1047-1071.

Strauss, G. L. (1970). Tristes trópicos. Buenos Aires: Eudeba.

Stuart, E. (1991). Todas las imágenes del consumismo: la política de estilo en la cultura contemporánea. México: Grijalbo.

Watson, S. (2009). The magic of the marketplace: sociality in a neglected public space. Urban Studies, 8(46), 1577-1591. 